\title{
PENGEMBANGAN SOFTWARE ANTI MISCHEM UNTUK MEREDUKSI MISKONSEPSI PESERTA DIDIK PADA MATERI HIDROLISIS GARAM DENGAN STRATEGI CONCEPTUAL CHANGE TEXT
}

\section{DEVELOPMENT OF SOFTWARE ANTI MISCHEM TO REDUCE MISCONCEPTION OF STUDENTS IN HYDROLYSIS OF SALT WITH CONCEPTUAL CHANGE TEXT STRATEGIES}

\author{
Zainab dan *Sukarmin \\ Jurusan Kimia FMIPA Universitas Negeri Surabaya \\ E-mail: sukarmin@unesa.ac.id
}

\begin{abstract}
Abstrak
Penelitian pengembangan ini bertujuan untuk mengetahui kelayakan pengembangan software anti mischem sebagai media untuk mereduksi miskonsepsi peserta didik dalam materi hidrolisis garam dengan strategi conceptual change text. Kelayakan software anti mischem ditinjau dari tiga aspek yaitu (1) validitas isi dan validitas konstruk software anti mischem yang ditentukan dari hasil validasi oleh validator (2) kepraktisan software anti mischem yang ditentukan dari hasil respon peserta didik dan didukung dengan hasil observasi aktivitas peserta didik (3) keefektifan software anti mischem yang ditentukan dari pergeseran pemahaman konsep peserta didik dari miskonsepsi menjadi paham konsep. Penelitian ini menggunakan metode Research and Development (R\&D). Subyek penelitian yang digunakan berjumlah 15 peserta didik kelas XI IPA SMAN 1 Krembung Sidoarjo. Hasil penelitian yang telah dilakukan, diperoleh persentase rata-rata hasil validasi isi sebesar 84,44\% dan validasi konstruk sebesar $82,74 \%$ yang masuk dalam kriteria sangat valid. Hasil persentase rata-rata respon peserta didik sebesar 92,59\% dan observasi aktivitas peserta didik sebesar 92,50\% yang masuk dalam kriteria sangat praktis. Hasil pergeseran pemahaman konsep peserta didik diperoleh rata-rata sebesar $83,65 \%$ yang masuk dalam kriteria sangat efektif, sehingga dapat disimpulkan software anti mischem yang telah dikembangkan dapat dinyatakan layak sebagai media untuk mereduksi miskonsepsi peserta didik pada materi hidrolisis garam dengan menggunakan strategi conceptual change text.
\end{abstract}

Kata Kunci: Software Anti Mischem, Reduksi Miskonsepsi, Hidrolisis Garam, Conceptual Change Text.

\begin{abstract}
Research development aims to determine the feasibility of developing anti-mischem software as a medium to reduce students misconceptions in hydrolysis of salt with conceptual change text strategies. Feasibility anti-mischem software in terms of three aspects that is: (1) content validity and construct validity of antimischem software from the results of validation by the validator, (2) practicability of anti-mischem software determined by the outcome of student response and supported by observation result of students' activities, (3) the effectiveness of anti-mischem software is determined from the shift in students' understanding of concepts from misconceptions to understanding concepts. This study using a method of Research and Development $(R \& D)$. Research subject used were 15 students $11^{\text {th }}$ grade science at SMAN 1 Krembung Sidoarjo. The results of the research that have been done, obtained an average percentage of the results of content validation of $84,44 \%$ and construct validation of $82,74 \%$ which fall into the very valid criteria. The results of the average percentange of students responses of $92,59 \%$ and observations of student activities of $92,50 \%$ which fall into very practical criteria. The results of the shift in understanding the concept of students obtained an average of $83,65 \%$ which is included in the criteria very effective, so it can be concluded that anti-mischem software that has been developed can be declared as a medium to reduce the student misconceptions on hydrolysis of salt using conceptual change text strategy.
\end{abstract}

Keywords: Software Anti Mischem, Reduce Misconception, Hydrolysis of Salt, Conceptual Change Text. 


\section{PENDAHULUAN}

Pendidikan ialah komponen yang penting dalam mengembangkan kemampuan serta menjadi tolak ukur kemajuan bangsa Indonesia. Pendidikan yaitu usaha sadar dan terencana untuk menciptakan situasi belajar dan proses pembelajaran supaya peserta didik secara aktif mengembangkan potensi didalam dirinya agar mempunyai keteguhan spiritual keagamaan, akhlak mulia, kepribadian, pengendalian diri, kecekatan dan kecerdasan yang dibutuhkan dirinya, masyarakat, bangsa dan negara, hal tersebut tercantum pada UU Republik Indonesia No.20 Tahun 2003 mengenai Sistem Pendidikan Nasional Pasal 1. Maka dari itu, pemerintah selalu menaikkan kualitas dan memperbaiki mutu pendidikan yang berada di Indonesia [1].

Pemerintah berusaha memperbaiki dan mengembangkan kurikulum dari tahun ke tahun untuk menaikkan kualitas dan memperbaiki mutu pendidikan. Kurikulum yang diterapkan yaitu kurikulum 2013 yang disempurnakan dalam segi pola pikir dimana kurikulum ini berpusat kepada peserta didik dan bergantung pada pemahaman konsep peserta didik. Peserta didik diharapkan dapat menguasai salah satu kemampuan yaitu kemampuan dalam memahami konsep yang benar [2].

Kimia ialah cabang dari ilmu pengetahuan alam yang mempelajari sifat, perubahan materi, struktur serta konsep dan teorinya [3]. Ilmu kimia tidak dapat lepas dari konsep, salah satunya adalah materi hidrolisis garam. Materi hidrolisis garam memiliki karakteristik bersifat abstrak dan kompleks. Karakteristik pada materi hidrolisis garam bisa menimbulkan kesulitan peserta didik untuk memahami materi hidrolisis garam, sehingga susah untuk menguasai konsep-konsep pada materi tersebut [4]. Maka dari itu, penjelasan mengenai materi kimia perlu dibangun konsep yang benar dan memerlukan pembelajaran kualitas. Apabila konsep yang dimiliki peserta didik tidak sesuai dengan konsep yang telah disepakati oleh para ahli maka yang terjadi ialah miskonsepsi.

Salah satu miskonsepsi materi hidrolisis garam yaitu peserta didik berfikir hidrolisis merupakan pelarutan garam di dalam air. Konsep yang benar yaitu hidrolisis merupakan reaksi antara kation/anion garam, atau keduanya dengan air [4]. Miskonsepsi dapat menyebabkan suatu konsep dimiliki peserta didik tidak bisa dihubungkan dengan konsep lainnya atau tidak bisa dihubungkan dengan realita sehingga konsep yang diterima tidak bermakna dan peserta didik tidak menerapkan konsep secara utuh, sehingga adanya miskonsepsi dalam suatu pembelajaran menyebabkan peserta didik kesulitan dalam proses belajar [5].

Peneliti telah melakukan pra-penelitian di tiga sekolah berbeda secara random pada kelas XII IPA semester ganjil tahun ajaran 2019-2020. Hasilnya menunjukkan bahwa di SMAN 1 Krembung peserta didik yang mengalami miskonsepsi pada hidrolisis total diperoleh persentase sebesar $83 \%, 82 \%$ pada hidrolisis parsial bersifat asam, $84 \%$ pada hidrolisis parsial bersifat basa, dan $85 \%$ pada garam bersifat netral. Pada SMAN 1 Porong diperoleh persentase sebesar $83 \%$ pada hidrolisis total, $84 \%$ pada hidrolisis parsial bersifat basa, $82 \%$ pada hidrolisis parsial bersifat asam dan $85 \%$ pada garam bersifat netral. Pada MAN Sidoarjo diperoleh persentase sebesar $82 \%$ pada hidrolisis total, $77 \%$ pada hidrolisis parsial bersifat asam, $90 \%$ pada hidrolisis parsial bersifat basa dan $83 \%$ pada garam bersifat netral.

Miskonsepsi dapat diketahui dengan melakukan tes diagnostik. Pada penelitian ini menggunakan four-tier diagnostic test untuk mendeteksi miskonsepsi peserta didik. Four-tier merupakan pengembangan dari tes diagnostik pilihan ganda 4 tingkat, dimana four-tier berisi: (1) soal pilihan ganda dimana mempunyai 4 pengecoh dan 1 kunci jawaban, (2) confidence rating dalam memilih jawaban, (3) alasan menjawab suatu soal, (4) confidence rating dalam memberi alasan [6].

Terdapat banyak upaya untuk mereduksi miskonsepsi dan memfasilitasi perubahan konsepsi peserta didik. Analogi, diskusi, pembelajaran yang menggunakan komputer, demonstrasi, penggunaan conceptual change text dan kerja kelompok termasuk pendekatan perubahan konsepsi [7]. Pada penelitian ini, 
peserta didik yang menderita miskonsepsi direduksi menggunakan strategi conceptual change text.

CCT merupakan strategi pembelajaran media didasarkan teori conceptual change milik Posner [8]. Dalam strategi pembelajaran CCT mempunyai 4 fase pembelajaran diantaranya: (1) memperlihatkan konsepsi peserta didik, (2) membuat conflict conceptual, (3) proses equilibrasi, (4) rekonstruksi konsep [9]. Fase-fase yang terdapat pada strategi CCT tersebut merujuk pada teori belajar konstruktivis, perkembangan kognitif piaget dan pemrosesan informasi.

Selain penggunaan strategi dan metode yang tepat, penggunaan media pembelajaran seperti software juga salah satu komponen pembelajaran yang sangat penting untuk mengurangi miskonsepsi dan meningkatkan pemahaman konsep. Hal tersebut dilihat dari analisis 10 soal yang diujikan diperoleh persentase pergeseran konsep peserta didik dari miskonsepsi menjadi paham konsep mencapai $\geq$ $61 \%$, dimana pergeseran miskonsepsi terendah terjadi soal nomor 1 dan 5 dengan persentase sebesar $66,67 \%$ dan tingkat pergeseran miskonsepsi tertinggi terjadi pada soal nomor 3 dan 10 dengan persentase sebesar 100\% [8].

Berdasarkan hasil penelitian sebelumnya, menunjukkan penggunaan software yang sudah dikembangkan bisa digunakan sebagai strategi mendeteksi miskonsepsi dan menurunkan miskonsepsi [10]. Berdasarkan uraian diatas peneliti ingin mengembangkan software untuk mereduksi peserta didik yang mengalami miskonsepsi. Berkaitan dengan hal tersebut, dilakukan penelitian yang bejudul "Pengembangan Software Anti Mischem untuk Mereduksi Miskonsepsi Peserta Didik pada Materi Hidrolisis Garam dengan Strategi Conceptual Change Text.

\section{METODE}

Penelitian ini menerapkan metode Research and Development (R\&D) Sugiyono dengan subyek penelitiannya terdiri dari 15 peserta didik SMA Negeri 1 Krembung Sidoarjo. Metode R\&D memiliki 10 langkah dalam prosedur penelitiannya, tetapi dalam pengembangan software untuk mereduksi miskonsepsi peserta didik pada materi hidrolisis garam hanya sampai pada tahap uji coba kelayakan produk. Berikut alur metode $R \& D$ yang ditunjukkan pada Gambar 1 .

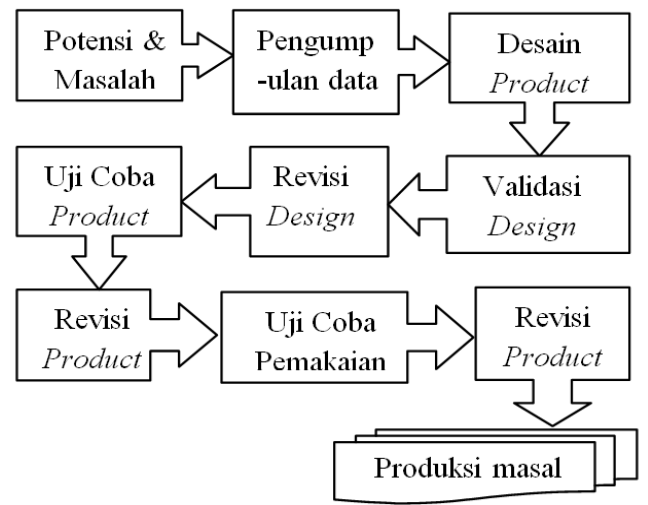

Gambar 1. Alur Metode R\&D [11].

Lembar telaah software, lembar validasi software, lembar angket respon peserta didik, lembar observasi aktivitas peserta didik dan lembar tes berfungsi sebagai alat dalam pengumpulan data.

Lembar telaah software berupa angket yang memuat kualitas software untuk mendeteksi dan mereduksi miskonsepsi peserta didik. Angket telaah digunakan untuk mendapatkan saran dari dosen kimia terhadap software. Lembar validasi software ini berupa angket yang digunakan untuk menilai kevalidan dari software yang dikembangkan dilihat dari kesesuaian berdasarkan kriteria validitas isi dan validitas konstruk sebagai media untuk mendeteksi dan mereduksi miskonsepsi. Angket validasi ini dinilai oleh 3 validator yaitu satu guru kimia dan dua dosen kimia.

Analisis data validitas dapat dilakukan dengan menghitung jumlah skor berdasarkan skala likert [12]. Berikut rumus yang digunakan untuk menentukan persentase dari hasil penilaian validasi dari masing-masing kriteria:

$$
\mathrm{P}(\%)=\frac{\text { skor yang diperoleh }}{\text { skor maksimal }} \times 100 \%
$$

Software anti mischem dinyatakan valid apabila interpretasinya $\geq 61 \%$.

Analisis data hasil respon peserta didik berfungsi mengetahui kepraktisan software yang dikembangkan untuk mendukung penilaian kevalidan software tersebut. Analisis data hasil 
respon peserta didik menggunakan skala Guttman yaitu menggunakan jawaban "Ya" dan "Tidak". Skor 1 jika "Ya" dan skor 0 jika "Tidak" [11]. Rumus menghitung persentase jawaban "Ya" dan "Tidak" sebagai berikut:

$\mathrm{P}(\%)=\frac{\text { jumlah respon untuk jawaban "Ya" }}{\text { jumlah seluruh peserta didik }} \times 100 \%$

Software anti mischem dinyatakan praktis apabila persentase respon yang menjawab "Ya" mencapai $\geq 61 \%$.

Analisis observasi terhadap aktivitas peserta didik berfungsi mendukung data hasil respon peserta didik, dimana data yang didapatkan dianalisis secara deskriptif kualitatif.

Analisis pergeseran konsepsi peserta didik digunakan untuk mengetahui keefektifan software anti mischem. Untuk mengetahui analisis pemahaman konsep peserta didik digunakan metode four-tier diagnostic test. Rumus yang digunakan untuk analisis pergeseran konsepsi peserta didik sebagai berikut:

$$
\mathrm{P}(\%)=\frac{\Sigma \text { pergeseran dari } M \text { ke } P K}{\Sigma M \text { awal }} \times 100 \%
$$

Software dinyatakan efektif jika hasil pergeseran dari miskonsepsi menjadi paham konsep mencapai $\geq 61 \%$.

\section{HASIL DAN PEMBAHASAN}

Berikut adalah hasil langkah
pengembangan software yang menggunakan
metode R\&D:

\section{a. Potensi dan Masalah}

Peneliti menemukan peserta didik yang menderita miskonsepsi materi hidrolisis garam di berbagai sekolah yaitu SMA Negeri 1 Krembung, SMA Negeri 1 Porong dan MA Negeri Sidoarjo. Pada setiap sekolah hubungan guru dengan peserta didik terjalin baik saat proses pembelajaran. Namun masalahnya, guru belum menemukan cara yang tepat untuk mereduksi miskonsepsi dalam materi hidrolisis garam. Hidrolisis garam merupakan materi kimia yang bersifat abstrak dan kompleks. Karakteristik pada hidrolisis garam memicu kesulitan peserta didik untuk memahami materi hidrolisis garam [4].

$$
\text { Guru memiliki peran mereduksi }
$$
miskonsepsi, sehingga guru harus menggunakan strategi penyembuhan yang sesuai dalam mereduksi miskonsepsi. Strategi penyembuhan yang berpotensi untuk mereduksi miskonsepsi peserta didik yaitu strategi perubahan konseptual (CCT). CCT merupakan strategi pembelajaran yang efektif dalam mereduksi miskonsepsi dikarenakan dapat membuat peserta didik sadar akan miskonsepsi yang dialaminya [9].

Software anti mischem dapat dijalankan melalui laptop yang mempunyai flash player. Software anti mischem dibuat dalam bentuk multimedia interaktif.

\section{b. Pengumpulan Data}

Menganalisis kebutuhan melalui studi literatur. Beberapa jurnal yang telah dikaji diantaranya konsep yang sering memicu miskonsepsi materi hidrolisis garam yaitu pengertian hidrolisis garam dan sifat garam [4]. Remidiasi dengan strategi CCT berhasil mereduksi miskonsepsi peserta didik secara signifikan menggeser persentase Miskonsepsi 2 menjadi paham konsep sebanyak 62 dan Miskonsepsi 3 menjadi paham konsep sebanyak 70 pada kelas XII IPA 2, sehingga strategi CCT efektif dalam mereduksi miskonsepsi [13].

Pra-penelitian dilakukan di SMA Negeri 1 Krembung kelas XII IPA semester ganjil dan XI IPA semester genap tahun ajaran 2019-2020 untuk mengetahui apakah terdapat miskonsepsi materi hidrolisis garam dan mengetahui data yang menderita miskonsepsi materi hidrolisis garam. Prapen dilakukan 2 kali dikarenakan subyek penelitian kelas XII IPA berada dalam masa ujian. Kelas XII IPA peserta didik yang mengalami miskonsepsi pada hidrolisis total diperoleh persentase sebesar $83 \%, 82 \%$ pada hidrolisis parsial bersifat asam, $84 \%$ pada hidrolisis parsifat bersifat basa dan $85 \%$ pada garam bersifat netral. Kelas XI IPA peserta didik yang mengalami miskonsepsi pada hidrolisis total diperoleh persentase sebesar $65 \%, 71 \%$ pada hidrolisis parsial dan $61 \%$ pada garam bersifat netral.

\section{c. Desain Produk}

Peneliti menyusun kisi-kisi soal pretestposttest, menyusun materi hidrolisis garam yang menggunakan strategi CCT serta menyusun rancangan desain software anti mischem sebagai 
tempat menampung soal pretest-posttest dan materi hidrolisis garam yang telah disusun. Berikut penjelasan secara lengkap mengenai desain software anti mischem:

a) Halaman Login

Halaman login terdapat kolom username dan kolom password, dimana peserta didik harus login dengan memasukkan NIS pada kolom username dan kode paket soal pada kolom password yang diberikan oleh peneliti/admin. Kemudian menekan tombol enterl klik tombol login. Halaman login software anti mischem ditunjukkan pada Gambar 2.

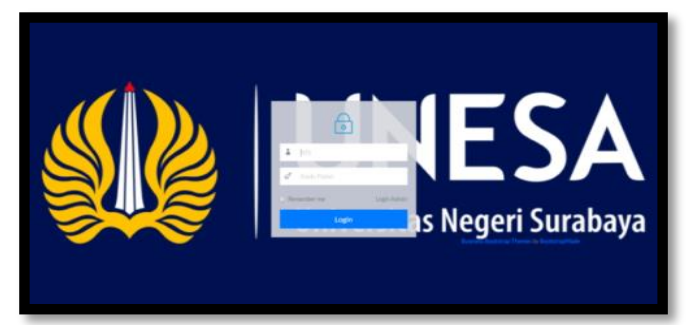

Gambar 2. Tampilan Halaman Login

b) Menu Petunjuk Penggunaan Software Anti Mischem

Peserta didik yang telah login dan berhasil masuk harus membaca petunjuk penggunaan software anti mischem. Tampilan petunjuk software anti mischem ditunjukkan pada Gambar 3.

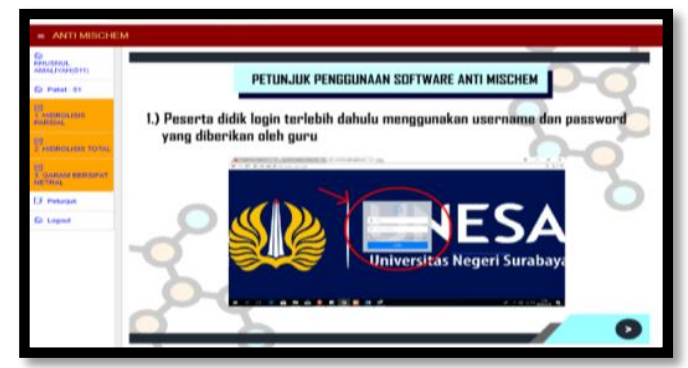

Gambar 3. Menu Petunjuk Software

c) Soal Pretest

Soal pretest digunakan untuk mendeteksi miskonsepsi peserta didik dengan metode four-tier diagnostic test. Pada saat peserta didik menjawab soal yang terdapat di konsep 1 dan terdeteksi miskonsepsi atau tidak paham konsep maka akan muncul warna merah pada bagian konsep 1 yang akan ditunjukkan pada Gambar 4, selanjutnya peserta didik harus melewati tahap penyembuhan yaitu CCT dengan menekan tombol help/materi.

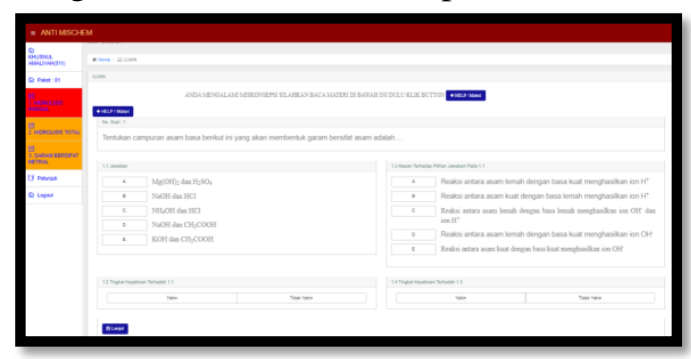

Gambar 4. Tampilan Soal Pretest

d) Materi dengan Strategi CCT

Strategi CCT digunakan untuk menyembuhkan peserta didik yang menderita miskonsepsi dan tidak paham konsep pada materi hidrolisis garam. Materi dengan strategi CCT berupa teks bacaan dan video mengenai hidrolisis garam. Tampilan strategi CCT ditunjukkan pada Gambar 5.

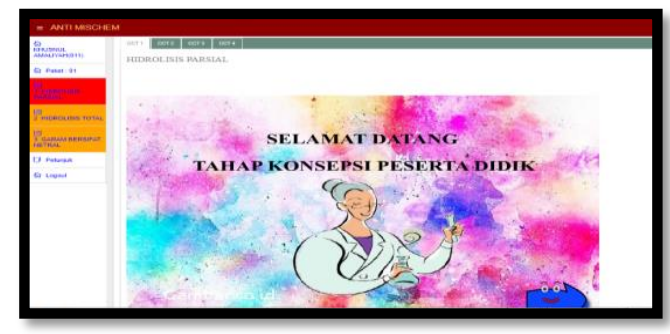

Gambar 5. Tampilan Materi Strategi CCT

e) Soal Posttest

Soal posttest berfungsi untuk mengetahui pergeseran konsepsi peserta didik dari yang menderita miskonsepsi atau tidak paham konsep ke paham konsep setelah melewati tahap CCT. Tampilan soal posttest ditunjukkan pada Gambar 6.

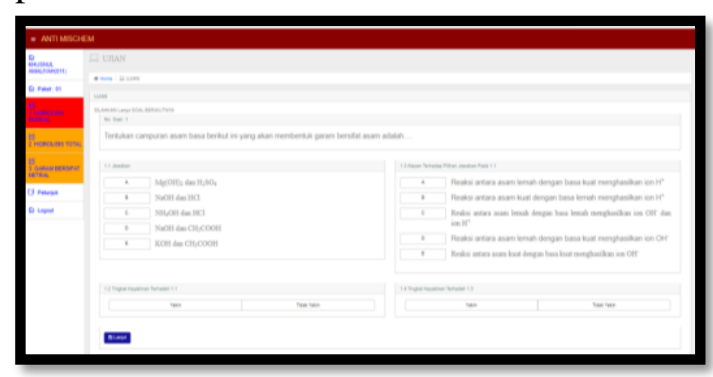

Gambar 6. Tampilan Soal Posttest

f) Menu Logout

Menu logout pada software berfungsi ketika peserta didik telah menyelesaikan semua konsep dengan baik maka bisa keluar dari software dengan menekan logout yang ditunjukkan pada Gambar 7. 


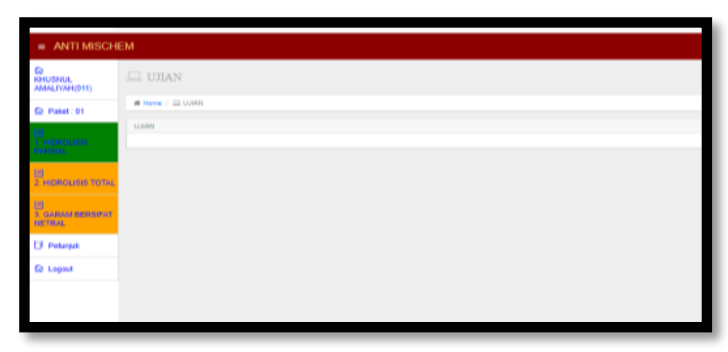

Gambar 7. Menu Logout pada Software

\section{d. Validasi Desain Software}

Tahap validasi ditinjau dari validasi isi dan validasi konstruk. Berikut data hasil validasi isi yang dilihat pada Tabel 1 dan data hasil validasi konstruk pada Tabel 2.

Tabel 1. Hasil Validasi Isi

\begin{tabular}{lcc}
\hline Kriteria Penilaian & $\begin{array}{c}\text { Persentase } \\
(\mathbf{\%})\end{array}$ & Kriteria \\
\hline $\begin{array}{l}\text { Mengetahui } \\
\text { kebenaran materi } \\
\text { dalam software }\end{array}$ & 83,33 & $\begin{array}{c}\text { Sangat } \\
\text { valid }\end{array}$ \\
$\begin{array}{l}\text { Mengetahui } \\
\text { terpenuhinya syarat } \\
\text { sebagai software } \\
\text { pembelajaran untuk }\end{array}$ & 85,55 & $\begin{array}{c}\text { Sangat } \\
\text { valid }\end{array}$ \\
$\begin{array}{l}\text { mereduksi } \\
\text { miskonsepsi }\end{array}$ & & \\
$\begin{array}{l}\text { Persentase rata-rata } \\
\text { ( } 84,44\end{array}$ & $\begin{array}{c}\text { Sangat } \\
\text { valid }\end{array}$ \\
\hline
\end{tabular}

Berdasarkan validasi isi software yang ditunjukkan pada Tabel 1 memiliki 2 kriteria penilaian. Pada kriteria penilaian pertama mempunyai empat aspek yang dinilai oleh validator, dimana mendapatkan persentase ratarata sebesar $83,33 \%$. Pada kriteria kedua mempunyai 6 aspek yang dinilai oleh validator mendapatkan persentase rata-rata sebesar $85,55 \%$.

Berdasarkan hasil validasi dari kedua kriteria penilaian mendapatkan persentase ratarata sebesar $84,44 \%$, sehingga hal tersebut termasuk dalam kategori valid.

Tabel 2. Hasil Validasi Konstruk

\begin{tabular}{lcc}
\hline \multicolumn{1}{c}{$\begin{array}{c}\text { Kriteria } \\
\text { Penilaian }\end{array}$} & $\begin{array}{c}\text { Persentase } \\
(\boldsymbol{\%})\end{array}$ & Kriteria \\
\hline $\begin{array}{l}\text { Tampilan } \\
\text { software }\end{array}$ & 83,33 & $\begin{array}{c}\text { Sangat } \\
\text { valid }\end{array}$ \\
$\begin{array}{l}\text { Bahasa yang } \\
\text { digunakan dalam }\end{array}$ & 82,22 & $\begin{array}{c}\text { Sangat } \\
\text { Valid }\end{array}$ \\
$\begin{array}{l}\text { software } \\
\text { Kepraktisan } \\
\text { penggunaan }\end{array}$ & 82,68 & $\begin{array}{c}\text { Sangat } \\
\text { Valid }\end{array}$ \\
\hline
\end{tabular}

\begin{tabular}{|c|c|c|}
\hline $\begin{array}{c}\text { Kriteria } \\
\text { Penilaian } \\
\end{array}$ & $\begin{array}{c}\text { Persentase } \\
(\%)\end{array}$ & Kriteria \\
\hline software & & \\
\hline $\begin{array}{l}\text { Persentase rata- } \\
\text { rata }\end{array}$ & 82,74 & $\begin{array}{l}\text { Sangat } \\
\text { valid }\end{array}$ \\
\hline
\end{tabular}

Berdasarkan validasi konstruk software yang ditunjukkan pada Tabel 2 memiliki 3 kriteria penilaian. Pada kriteria penilaian pertama mempunyai empat aspek yang dinilai oleh validator dengan rata-rata persentase sebesar $83,33 \%$. Pada kriteria kedua mempunyai 3 aspek yang mendapatkan persentase rata-rata sebesar $82,22 \%$. Pada kriteria ketiga mempunyai 5 aspek yang mendapatkan persentase sebesar $82,68 \%$.

Berdasarkan hasil validasi dari ketiga kriteria penilaian diperoleh persentase rata-rata sebesar $82,74 \%$, sehingga hal tersebut termasuk kategori valid.

\section{e. Revisi Desain}

Tahap revisi desain dilakukan apabila mendapatkan saran dan komentar yang diberikan oleh validator. Berikut beberapa hasil revisi:

a) Mengkunci tombol lanjut

b) Ukuran flash diperbesar agar materi terlihat dengan jelas dalam software

c) Memberi tombol back pada flash

d) Memperbaiki kalimat perintah dalam materi flash agar jelas dan mudah untuk dimengerti

\section{f. Uji Coba Produk}

Tujuan dilakukannya uji coba produk yaitu untuk mengetahui kepraktisan dan keefektifan software anti mischem.

Data respon peserta didik didapatkan dari angket yang telah diberikan oleh peneliti pada 15 peserta didik kelas XI MIA 1 SMA Negeri 1 Krembung. Berikut data hasil respon peserta didik yang ditunjukkan Tabel 3.

Tabel 3. Hasil Respon Peserta Didik

\begin{tabular}{|c|c|c|}
\hline Aspek yang Dinilai & $\begin{array}{c}\text { Persentase } \\
(\%)\end{array}$ & Kriteria \\
\hline $\begin{array}{lr}\text { Software } & \text { anti } \\
\text { miskonsepsi } & \text { sangat } \\
\text { menarik } & \end{array}$ & 100 & $\begin{array}{l}\text { Sangat } \\
\text { praktis }\end{array}$ \\
\hline $\begin{array}{l}\text { Penampilan software } \\
\text { sangat menarik }\end{array}$ & 100 & $\begin{array}{l}\text { Sangat } \\
\text { praktis }\end{array}$ \\
\hline $\begin{array}{l}\text { Petunjuk software } \\
\text { mudah dipahami }\end{array}$ & 86,67 & $\begin{array}{l}\text { Sangat } \\
\text { praktis }\end{array}$ \\
\hline Bahasa yang & 93,33 & Sangat \\
\hline
\end{tabular}




\begin{tabular}{|c|c|c|}
\hline Aspek yang Dinilai & $\begin{array}{c}\text { Persentase } \\
(\%)\end{array}$ & Kriteria \\
\hline $\begin{array}{ll}\text { digunakan } & \text { mudah } \\
\text { dipahami } & \end{array}$ & & praktis \\
\hline $\begin{array}{l}\text { Soal } \\
\text { dimengerti }\end{array}$ & 86,67 & $\begin{array}{l}\text { Sangat } \\
\text { praktis }\end{array}$ \\
\hline $\begin{array}{l}\text { Cara menggunakan } \\
\text { software mudah }\end{array}$ & 93,33 & $\begin{array}{l}\text { Sangat } \\
\text { praktis }\end{array}$ \\
\hline $\begin{array}{l}\text { Software ini membuat } \\
\text { saya lebih tertarik } \\
\text { dalam belajar kimia }\end{array}$ & 93,33 & $\begin{array}{l}\text { Sangat } \\
\text { praktis }\end{array}$ \\
\hline $\begin{array}{l}\text { Software } \\
\text { meningkatkan }\end{array}$ & 93,33 & $\begin{array}{l}\text { Sangat } \\
\text { praktis }\end{array}$ \\
\hline $\begin{array}{ll}\text { semangat } & \text { dalam } \\
\text { belajar kimia } & \end{array}$ & & \\
\hline $\begin{array}{l}\text { Saya senang dalam } \\
\text { menjawab soal yang } \\
\text { terdapat dalam } \\
\text { software }\end{array}$ & 86,67 & $\begin{array}{l}\text { Sangat } \\
\text { praktis }\end{array}$ \\
\hline Rata-rata persentase & 92,59 & $\begin{array}{l}\text { Sangat } \\
\text { praktis }\end{array}$ \\
\hline
\end{tabular}

Berdasarkan Tabel 3 data respon peserta didik memilki 9 aspek yang dinilai. Pada aspek pertama dan kedua bertujuan untuk mengidentifikasi software anti miskonsepsi dapat menarik rasa ingin tahu peserta didik dengan masing-masing persentase sebesar $100 \%$. Data tersebut membuktikan bahwa peserta didik tertarik pada software sebagai media pembelajaran yang bisa menumbuhkan rasa ingin tahu peserta didik, dimana merupakan salah satu dasar dalam mengembangkan media pembelajaran [14]. Aspek ketiga, keempat dan kelima bertujuan untuk mengetahui kejelasan dalam software dengan masing-masing persentase sebesar 86,67\%; 93,33\% dan 86,67\%. Data tersebut menunjukkan bahwa sebagian besar peserta didik dapat memahami bahasa yang berada dalam petunjuk software anti mischem. Pada aspek keenam bertujuan untuk mengetahui tingkat kemudahan dalam penggunaan software dengan persentase sebesar 93,33\%. Data tersebut menunjukkan sebagian besar peserta didik bisa menggunakan software dengan mudah. Peneliti ingin mengetahui seberapa besar kemudahan software dikarenakan merupakan salah satu syarat intruksional media yang edukatif [14]. Pada aspek ketujuh, kedelapan dan kesembilan bertujuan untuk mengetahui tingkat motivasi belajar peserta didik dengan menggunakan software anti miskonsepsi dengan masing-masing persentase sebesar 93,33\%; 93,33\% dan 86,67\%. Peneliti ingin mengetahui seberapa besar tingkat motivasi peserta didik dikarenakan salah satu dasar dalam menngembangkan media yaitu menumbukan motivasi [14].

Berdasarkan data hasil respon peserta didik yang ditunjukkan pada Tabel 3 diperoleh persentase sebesar 92,59\%, sehingga software anti mischem yang dikembangkan dapat dinyatakan praktis.

Hasil observasi aktivitas peserta didik terhadap software anti mischem digunakan untuk mendukung hasil respon peserta didik yang ditunjukkan pada Tabel 4.

Tabel 4. Hasil Observasi Aktivitas Peserta Didik

\begin{tabular}{|c|c|c|}
\hline $\begin{array}{c}\text { Aspek yang } \\
\text { Diamati }\end{array}$ & $\begin{array}{c}\text { Persentase } \\
(\%)\end{array}$ & Kriteria \\
\hline $\begin{array}{l}\text { Peserta didik dapat } \\
\text { mengoperasikan } \\
\text { software dengan } \\
\text { baik }\end{array}$ & 86,67 & $\begin{array}{l}\text { Sangat } \\
\text { praktis }\end{array}$ \\
\hline $\begin{array}{l}\text { Peserta didik } \\
\text { mengoperasikan } \\
\text { tombol-tombol } \\
\text { pada software } \\
\text { dengan baik }\end{array}$ & 86,67 & $\begin{array}{l}\text { Sangat } \\
\text { praktis }\end{array}$ \\
\hline $\begin{array}{l}\text { Peserta didik tidak } \\
\text { meninggalkan } \\
\text { ruangan selama uji } \\
\text { coba produk }\end{array}$ & 100 & $\begin{array}{l}\text { Sangat } \\
\text { praktis }\end{array}$ \\
\hline $\begin{array}{l}\text { Peserta didik } \\
\text { mengajukan } \\
\text { pertanyaan pada } \\
\text { tampilan tertentu }\end{array}$ & 93,33 & $\begin{array}{l}\text { Sangat } \\
\text { praktis }\end{array}$ \\
\hline $\begin{array}{l}\text { Peserta didik } \\
\text { mengajukan } \\
\text { pertanyaan }\end{array}$ & 100 & $\begin{array}{l}\text { Sangat } \\
\text { praktis }\end{array}$ \\
\hline $\begin{array}{l}\text { Peserta didik } \\
\text { membaca dengan } \\
\text { seksama CCT yang } \\
\text { disajikan }\end{array}$ & 86,67 & $\begin{array}{l}\text { Sangat } \\
\text { praktis }\end{array}$ \\
\hline $\begin{array}{lr}\text { Peserta } & \text { didik } \\
\text { membuka } & \text { atau } \\
\text { mengakhiri } & \end{array}$ & 100 & $\begin{array}{l}\text { Sangat } \\
\text { praktis }\end{array}$ \\
\hline $\begin{array}{l}\text { software tanpa } \\
\text { bantuan teman atau } \\
\text { guru }\end{array}$ & & \\
\hline $\begin{array}{l}\text { Peserta didik } \\
\text { termotivasi } \\
\text { mempelajari } \\
\text { tampilan software }\end{array}$ & 86,67 & $\begin{array}{l}\text { Sangat } \\
\text { praktis }\end{array}$ \\
\hline
\end{tabular}




\begin{tabular}{lcc}
\hline \multicolumn{1}{c}{$\begin{array}{c}\text { Aspek yang } \\
\text { Diamati }\end{array}$} & $\begin{array}{c}\text { Persentase } \\
(\boldsymbol{\%})\end{array}$ & Kriteria \\
\hline $\begin{array}{l}\text { Rata-rata } \\
\text { persentase }\end{array}$ & 92,50 & $\begin{array}{l}\text { Sangat } \\
\text { praktis }\end{array}$ \\
\hline
\end{tabular}

Lembar observasi aktivitas peserta didik memiliki delapan aspek yang diamati oleh observer. Berdasarkan Tabel 4 diperoleh hasil observasi aktivitas peserta didik rata-rata persentase sebesar 92,50\%, hal tersebut dikategorika sangat praktis sehingga software anti mischem yang dikembangkan dapat dikatakan praktis.

Miskonsepsi yang diderita peserta didik dapat menyebabkan suatu konsep yang dimilikinya tidak dapat dihubungkan dengan konsep lain sehingga konsep yang diterima tidak bermakna, akan tetapi miskonsepsi masih bisa direduksi dengan strategi CCT. CCT mempunyai 4 fase pembelajaran diantaranya: (1) memperlihatkan konsepsi peserta didik, (2) membuat conflict conceptual, (3) proses equilibrasi, (4) rekonstruksi konsep [9]. Pada fase pertama peserta didik diberitahu bahwa konsep yang dimilikinya tidak sesuai dengan konsep para ahli dan harus melalui tahap penyembuhan. Fase kedua memberikan pertanyaan yang menimbulkan konflik kognitif, dimana konflik ini dapat mengakibatkan skema yang dimiliki oleh peserta didik menjadi tidak seimbang. Pada keadaan tidak seimbang ini peserta didik diharuskan mengkonstruksi gagasannya yang salah [15]. Fase ketiga peserta didik akan diberitahu penjelasan konsep yang benar dan sesuai dengan para ahli. Fase keempat memberikan peserta didik persoalan yang bisa diselesaikan dengan menerapkan konsep yang sesuai dengan para ahli.

Fase strategi CCT merujuk pada teori belajar konstruktivis, perkembangan kognitif piaget dan pemrosesan informasi. Strategi kontruktivis merupakan strategi yang sesuai dengan strategi perubahan konseptual yang akan digunakan dalam mengembangkan software dikarenakan di dalam strategi ini peserta didik dibimbing menemukan konsep yang benar [16]. Tahapan perkembangan kognitif dalam teori piaget sesuai dengan tahapan strategi perubahan konseptual yang akan menjadi acuan dalam pengembangan software anti mischem, dimana tahapan dimulai dari setiap peserta didik telah memiliki konsep yang diketahuinya dari interaksi dengan lingkungan dan pada setiap peserta didik memiliki konsep yang berbeda. Hal ini menyebabkan peserta didik mengalami miskonsepsi. Untuk mengubah konsep yang berbeda yang dimiliki peserta didik dapat diatasi melalui proses adaptasi, kemudian akomodasi atau asimilasi dan ekuilibrium [17]. Teori pemrosesan informasi yakni teori kognitif yang menjelaskan pemrosesan, penyimpanan dan pemanggilan kembali [18]. Teori pemrosesan informasi ini menjadi dasar dalam pengembangan software anti mischem karena diharapkan mampu membantu peserta didik dalam memproses informasi ke momeri jangka panjang melalui proses pengideraan dan pengkodean secara berulang.

Hasil pergeseran pemahaman konsep peserta didik didapat dari hasil mengerjakan soal pretest dan hasil mengerjakan soal posttest. Berikut hasil pergeseran konsepsi peserta didik yang dilihat pada Tabel 5, Tabel 6 dan Tabel 7 .

Tabel 5. Hasil Pergeseran Konsepsi Hidrolisis Parsial

\begin{tabular}{lc}
\hline $\begin{array}{l}\text { Hasil Pergeseran } \\
\text { Konsepsi Peserta } \\
\text { Didik }\end{array}$ & $\begin{array}{c}\text { Persentase Pergeseran } \\
\text { Miskonsepsi }(\%)\end{array}$ \\
\hline PK-TPK $=0$ & $\mathrm{P}(\%)=\frac{\Sigma M-P K}{\sum M \text { awal }} \times 100 \%$ \\
PK-M $=0$ & $\mathrm{P}(\%)=\frac{37}{45} \times 100 \%$ \\
PK-PK $=5$ & $=82,22$ \\
TPK-PK $=10$ & \\
TPK-M $=0$ & \\
TPK-TPK $=0$ & \\
M-PK $=37$ & \\
M-TPK $=0$ & \\
M-M $=8$ & \\
\hline
\end{tabular}

Berdasarkan hasil pergeseran konsepsi peserta didik hidrolisis parsial yang ditunjukkan pada tabel 5 diketahui pergeseran konsepsi dari yang PK-PK ada sebanyak 5 jawaban, TPK-PK ada sebanyak 10 jawaban, M-PK ada sebanyak 37 jawaban dan M-M ada sebanyak 8. Jumlah jawaban peserta didik yang menderita $\mathrm{M}$ awal ada sebanyak 45 dan jumlah jawaban mengalami pergeseran M ke PK sebanyak 37, sehingga diperoleh persentase pergeseran konsepsinya 
sebesar $82,22 \%$ yang termasuk kategori sangat efektif. Berikut contoh soal yang mengalami miskonsepsi pada konsep hidrolisis parsial:

Perhatikan reaksi dibawah ini:

$$
\begin{aligned}
& \mathrm{CH}_{3} \mathrm{COOK}_{(a q)} \rightarrow \mathrm{CH}_{3} \mathrm{COO}^{-}(a q)+\mathrm{K}^{+}(a q) \\
& \mathrm{CH}_{3} \mathrm{COO}^{-}(a q)+\mathrm{H}_{2} \mathrm{O}(l) \rightarrow \mathrm{CH}_{3} \mathrm{COOH}(a q)+ \\
& \mathrm{OH}^{-}(a q) \\
& \mathrm{K}^{+}(a q)+\mathrm{H}_{2} \mathrm{O}(\mathrm{l}) \rightarrow(\text { tidak bereaksi }) \\
& \text { Analisislah data reaksi tersebut, dan reaksinya } \\
& \text { termasuk dalam jenis hidrolisis...... }
\end{aligned}
$$

Tabel 6. Hasil Pergeseran Konsepsi Peserta Didik Hidrolisis Total

\begin{tabular}{lc}
\hline $\begin{array}{c}\text { Hasil Pergeseran } \\
\text { Konsepsi }\end{array}$ & $\begin{array}{c}\text { Persentase Pergeseran } \\
\text { Miskonsepsi }(\%)\end{array}$ \\
\hline PK-TPK $=0$ & $\mathrm{P}(\%)=\frac{\Sigma M-P K}{\sum M \text { awal }} \times 100 \%$ \\
PK-M $=0$ & $\mathrm{P}(\%)=\frac{41}{48} \times 100 \%$ \\
PK-PK $=3$ & $=85,41$ \\
TPK-PK $=9$ & \\
TPK-M $=0$ & \\
TPK-TPK $=0$ & \\
M-PK $=41$ & \\
M-TPK $=0$ & \\
M-M $=7$ & \\
\hline
\end{tabular}
peserta didik hidrolisis total yang ditunjukkan pada Tabel 6 diketahui pergeseran konsepsi dari yang mengalami PK-PK ada sebanyak 3 jawaban, TPK-PK ada sebanyak 9 jawaban, M-PK ada sebanyak 41 jawaban dan M-M ada sebanyak 7. Jumlah jawaban peserta didik yang menderita $\mathrm{M}$ awal ada sebanyak 48 dan jumlah jawaban mengalami pergeseran konsepsi hidrolisis total dari $M$ ke PK ada sebanyak 41, sehingga diperoleh persentase pergeseran konsepsinya sebesar $85,41 \%$ yang masuk dalam kategori sangat efektif. Berikut contoh soal yang mengalami miskonsepsi pada hidrolisis total:

Perhatikan data reaksi kimia berikut, reaksi berikut merupakan reaksi garam yang mengalami hidrolisis.

$$
\text { a. } \begin{aligned}
& \mathrm{NH}_{4} \mathrm{~F}(a q) \rightarrow \mathrm{NH}_{4}^{+}(a q)+\mathrm{F}^{-}(a q) \\
& \mathrm{NH}_{4}^{+}(a q)+\mathrm{H}_{2} \mathrm{O}(\mathrm{l}) \rightarrow \mathrm{NH}_{4} \mathrm{OH}(a q)+\mathrm{H}^{+}(a q) \\
& \mathrm{F}^{-}(a q)+\mathrm{H}_{2} \mathrm{O}(l) \rightarrow \mathrm{HF}(a q)+\mathrm{OH}^{-}(a q)
\end{aligned}
$$

b. $\mathrm{NH}_{4} \mathrm{Cl}(a q) \rightarrow \mathrm{NH}_{4}^{+}(a q)+\mathrm{Cl}^{-}(a q)$

$\mathrm{NH}_{4}{ }^{+}(a q)+\mathrm{H}_{2} \mathrm{O}(\mathrm{l}) \rightarrow \mathrm{NH}_{4} \mathrm{OH}(a q)+\mathrm{H}^{+}(a q)$

$\mathrm{Cl}^{-}(\mathrm{aq})+\mathrm{H}_{2} \mathrm{O}(\mathrm{l}) \rightarrow($ tidak bereaksi $)$

c. $\mathrm{NaCN}(a q) \rightarrow \mathrm{Na}^{+}(a q)+\mathrm{CN}^{-}(a q)$

$\mathrm{CN}^{-}(a q)+\mathrm{H}_{2} \mathrm{O}(a q) \rightarrow \mathrm{HCN}(a q)+\mathrm{OH}^{-}(a q)$

$\mathrm{Na}^{+}(a q)+\mathrm{H}_{2} \mathrm{O}(l) \rightarrow($ tidak bereaksi $)$
Dari data di atas dapat disimpulkan bahwa reaksi hidrolisis total adalah...

Tabel 7. Hasil Pergeseran Konsepsi Peserta Didik Garam Bersifat Netral

\begin{tabular}{lc}
\hline $\begin{array}{c}\text { Hasil Pergeseran } \\
\text { Konsepsi }\end{array}$ & $\begin{array}{c}\text { Persentase Pergeseran } \\
\text { Miskonsepsi (\%) }\end{array}$ \\
\hline PK-TPK $=0$ & $\mathrm{P}(\%)=\frac{\Sigma M-P K}{\Sigma M \text { awal }} \times 100 \%$ \\
PK-M $=0$ & $\mathrm{P}(\%)=\frac{40}{48} \times 100 \%$ \\
PK-PK $=4$ & $=83,33$ \\
TPK-PK $=8$ & \\
TPK-M $=0$ & \\
TPK-TPK $=0$ & \\
M-PK $=40$ & \\
M-TPK $=0$ & \\
$M-M=8$ & \\
\hline
\end{tabular}

Berdasarkan hasil pergeseran konsepsi peserta didik garam bersifat netral (tidak terhidrolisis) yang ditunjukkan pada Tabel 7 diketahui pergeseran konsepsi dari yang mengalami PK-PK ada sebanyak 4 jawaban, TPK-PK ada sebanyak 8 jawaban, M-PK ada sebanyak 40 jawaban dan M-M ada sebanyak 8 jawaban. Jumlah jawaban peserta didik yang menderita $\mathrm{M}$ awal ada sebanyak 48 dan jumlah jawaban mengalami pergeseran konsepsi garam bersifat netral dari M menjadi PK sebanyak 40, sehingga diperoleh persentase pergeseran konsepsinya sebesar 83,33\% yang dikategorikan sangat efektif. Berikut contoh soal yang mengalami miskonsepsi pada garam bersifat netral:

Diketahui beberapa jenis garam:

$\mathrm{FeCl} 3, \mathrm{NH}_{4} \mathrm{CN}, \mathrm{KCl}, \quad \mathrm{Na}_{2} \mathrm{SO}_{4}, \mathrm{Na}_{2} \mathrm{CO}_{3}, \mathrm{NaCl}$, $\mathrm{CH}_{3} \mathrm{COONa}, \mathrm{NH}_{4} \mathrm{Cl}$

Garam yang terbentuk dari reaksi asam kuat dan basa kuat yaitu.........

\section{SIMPULAN}

Berdasarkan hasil riset yang sudah dilakukan, maka pengembangan software anti mischem bisa dikatakan layak sebagai media untuk mereduksi miskonsepsi peserta didik materi hidrolisis garam yang ditinjau dari segi kevalidan, kepraktisan dan keefektifan dengan rincian sebagai berikut:

1) Validitas software yang dilakukan oleh 3 validator berdasarkan hasil validasi isi didapatkan persentase rata-rata sebesar $84,44 \%$ yang dikategorikan sangat valid dan 
hasil validasi konstruk diperoleh persentase rata-rata sebesar $82,74 \%$ yang dikategorikan sangat valid, sehingga software yang telah dikembangkan dinyatakan valid.

2) Kepraktisan software ditinjau dari hasil respon peserta didik diperoleh persentase sebesar ratarata sebesar 92,59\% yang dikategorikan sangat praktis dan didukung dengan hasil observasi aktivitas peserta didik didapatkan persentase rata-rata sebesar $92,50 \%$ yang dikategorikan sangat praktis, sehingga software yang telah dikembangkan dinyatakan praktis.

3) Keefektifan software ditinjau dari pergeseran pemahaman konsep peserta didik dari miskonsepsi menjadi paham konsep didapatkan persentase rata-rata sebesar $83,65 \%$ yang dikategorikan sangat efektif, sehingga software yang telah dikembangkan dinyatakan efektif.

\section{DAFTAR PUSTAKA}

1. Kementerian Riset, Teknologi dan Pendidikan Tinggi. 2006. Undang-Undang Republik Indonesia Nomor 20 Tahun 2003 Tentang Sistem Pendidikan Nasional. http://www.kelembagaan.ristekdikti.go.id/wpc ontent/uploads/2016/08/UU no 20 th 2003.p df. Diakses 11 Maret 2019.

2. Kementrian Riset, Teknologi, dan Pendidikan Tinggi. 2013. Peraturan Menteri Pendidikan dan Kebudayaan Republik Indonesia Nomor 69 Tahun 2003.

http://biologi.fkip.uns.ac.id/wpconcent/uploads/2013/08/PDK-2013-69Kerangka-Dasar-Kurikulum-KompetensiSMA-pdf. Diakses 11 Maret 2019.

3. Effendy,U.O. 2007. Ilmu Komunikasi (teori dan praktek). Bandung: PT. Remaja Rosdakarya.

4. Maratusholihah, N. F., Rahayu, S., \& Fajaroh, F. 2017. Analisis Miskonsepsi Siswa SMA pada Materi Hidrolisis Garam dan Larutan Penyangga. Jurnal Pendidikan, Vol. 2, No. 7, pp. 919-926.

5. Ibrahim, Muslimin. 2012. Konsep, Miskonsepsi dan Cara Pembelajarannya. Surabaya: Unesa University Press.

6. Fariyani, Q., Rusilowati, A., Sugiarto. 2015. Pengembangan Four-Tier Diagnostic Test Untuk Mengungkap Miskonsepsi Fisika Siswa
Sma Kelas X. Journal of Innovative Science Education, Vol. 4, No. 2, pp. 41-49.

7. Guzzetti, B. J. 2000. Learning Counter Intuitive Science Concepts: What Have We Learned from Over a Decade of Research. Journal Reading and Writing Quartely, Vol. 16, No. 2, pp. 89-98.

8. Sugiarti, F., \& Sukarmin. 2019. Mendeteksi dan Mereduksi Miskonsepsi dengan Menggunakan Software Dered Misequilibri pada Materi Kesetimbangan Kimia. Unesa Journal of Chemical Education, Vol. 8, No. 1, pp. 94-100.

9. Kumalaningtias, R., \& Sukarmin. 2019. Pengembangan Software Anti MCB dengan Strategi Conceptual Change Text untuk Mereduksi Miskonsepsi pada Materi Ikatan Kimia. Unesa Journal of Chemical Education, Vol.8, No.3, pp.420-426.

10.Suprianto dan Sukarmin. 2016. Pengembangan Software Pengukur Tingkat Konflik Kognitif Kimia. Unesa Journal of Chemical Education, Vol. 5, No. 2, pp. 359-366.

11.Sugiyono. 2017. Metode Penelitian Kebijakan: Pendekatan Kuantitatif, Kualitatif, Kombinasi $R \& D$ dan Penelitian Evaluasi. Bandung: Alfabeta.

12.Riduwan. 2015. Skala Pengukuran VariabelVariabel Penelitian. Bandung: Alfabeta.

13.Nikmah, K. 2015. Penerapan Strategi Pembelajaran Conceptual Change untuk Meremediasi Miskonsepsi pada Konsep Asam-Basa Siswa Kelas XII IPA SMAN 1 Waru Sidoarjo. Unesa Journal of Chemical Education, Vol. 4, No. 3, pp. 541-550.

14.Prastya, A. 2016. Strategi Pemilihan Media Pembelajaran Bagi Seorang Guru. Prosiding Temu Ilmiah Nasional Guru, Vol. 1, No. 8, pp. 294-302.

15.Suparno, Paul. 2013. Miskonsepsi dan Perubahan Konsep dalam Pendidikan Fisika. Jakarta: Gramedia.

16.Dahar, R.W. 2011. Teori-Teori Belajar dan Pembelajaran. Jakarta: Erlangga.

17.Nur, M. 2004. Teori-Teori Perkembangan Kognitif Edisi 2. Surabaya: UNESA PRESS.

18. Robert E, Slavin. 2000. Educational Psychology: Theory and Practice. New Jersey: Pearson Education. 